\title{
Reducing of energy consumption for the object's motion with designed optimum control
}

\author{
Alexander Bokhonsky ${ }^{1}$, Natalia Varminskaya ${ }^{2,}$, and Aleksandr Ryzhkov ${ }^{1}$ \\ ${ }^{1}$ Department of Technical Mechanics and Mechanical Engineering, Sevastopol State University, \\ Sevastopol, 299038, Russian Federation \\ ${ }^{2}$ Department of Physics and General Technical Disciplines, Black Sea Higher Naval School named after \\ P.S.Nakhimov, Sevastopol, 299028, Russian Federation
}

\begin{abstract}
The tendency of energy consumption decreasing for the designed optimal controls is revealed in dependence on the degree of the polynomial describing the control (acceleration) for the object's translational motion.
\end{abstract}

\section{Introduction}

Methods for solving problems, concerning object motion optimal control, usually involve justified optimality criteria usage, compilation the motion differential equations, consideration of constraints, and, finally, the use well-known methods of the classical optimal control theory.

The monographs of A.G. Butkovsky, N.N. Krasovsky, I.A. Karnovsky, Yu.M. Pochtman, V.A. Troitsky, F.L. Chernousko [1 - 5] and others are devoted to the optimal control of elastic systems motion and oscillations.

An important milestone in the optimal control theory evolution was the Pontryagin maximum principle discovery and its subsequent effective applications to the urgent technical problems [6].

Publications [7 - 10] are dedicated to the study of the designing features of the translational accelerations of absolutely rigid and deformable objects motions. In monograph [11], using the algorithm for solving the complete inverse problem of the variational calculus (reconstruction from the initial analytical function to the Euler equation and the functionalcriterion), controls for translational motion of elastic objects were found, for example, from the initial state of absolute quiescence to the final state of absolute quiescence. For the first time, it was shown that the designed control (acceleration) leads to the energy decrease for the optimal control implementation in comparison, for example, with known solution obtained by the variational method of the optimal control theory.

In [7], using a third-degree polynomial for control function, attention was also paid to the energy saving potential.

In works [8 - 12], a possible energy decrease for the optimal control of the "accelerationdeceleration" type is confirmed when an elastic object is moving at an adjusted distance for

* Corresponding author: nvarminska@,gmail.com 
an acceptable time determined from the moment ratios for relative motion (transcendental equations).

However, the control energy decreasing with the increasing of a degree of the polynomials, which describe the constructed controls (translational accelerations), still remains insufficiently studied.

The purpose of this research is to assess the influence of the polynomial degree of the optimal control on energy supply for the object motion.

\section{Algorithm for reversible designing of translational control (acceleration)}

1. The goal of control problem: an object motion (mass $m=1 \mathrm{~kg}$ ) from initial state of quiescence $\left(S_{e}(0)=0, V_{e}(0)=0\right)$ to a new state of quiescence $\left(S_{e}(T)=L, V_{e}(T)=0\right)$ for a fixed time $T$, where $S_{e}, V_{e}$ are displacement and speed, $L$ is the distance over which the object is moving.

2. Skew symmetry conditions for the acceleration (control):

$$
U_{e}(0)=a, \quad U_{e}(T)=-a ; \quad \int_{0}^{T / 2} U_{e}(t) d t+\int_{T / 2}^{T} U_{e}(t) d t=0,
$$

where $a=$ const.

3. Additional skew symmetry conditions:

$$
U_{e}\left(\frac{T}{2}\right)=0, \quad \frac{d^{n_{1}} U_{e}}{d t^{n_{1}}}=0
$$

where $n_{l}=1 \ldots 9$.

The parameter $a$ can be found both when solving a system of algebraic equations, or set in advance.

4. The following polynomial is taken as a control (acceleration) here:

$$
U_{e}(t)=\sum_{i=1}^{12} C_{i} \cdot t^{i-1}
$$

where $C_{i}=$ const.

5. After determining the constants, the polynomial is factorized and then takes the form

$$
U_{e}(t)=\frac{a^{\prime \prime}(T-2 t)^{\prime \prime}}{T^{\prime \prime}}
$$

where $a^{\prime \prime}=\frac{26 L}{T^{2}}$.

Moreover, $V_{e}(t)=\int U_{e}(t) d t$ and $S_{e}(t)=\int V_{e}(t) d t$. The formulas for displacement and velocity are rather cumbersome and therefore are not given here. For (1), the Euler equation is $\frac{d^{12} U_{e}(t)}{d t^{12}}=0$ and the criterion-functional takes the form

$$
J=\int_{0}^{T}\left(\frac{d^{6} U_{e}}{d t^{6}}\right)^{2} d t
$$




\section{Estimates of the constructed optimal motion on a scale of criteria}

1. Action according to Lagrange $J_{1}=\int_{0}^{T} V_{e}^{2} d t=\frac{1,04 L^{2}}{T}$.

2. Control energy intensity

$$
J_{2}=2 \cdot \int_{0}^{T / 2} U_{e}(t) V_{e}(t) d t=\frac{1,1736 L^{2}}{T^{2}} .
$$

3. Power norm $\quad J_{3}=\int_{0}^{T} U_{e}^{2} d t=\frac{29,39 L^{2}}{T^{3}}$.

4. Energy-action $J_{4}=E D=J_{1} \cdot J_{2}=\frac{1,2205 L^{4}}{T^{3}}$.

5. Control graph area (absolute value) $J_{5}=2 \int_{0}^{T / 2} U_{e} d t=\frac{2,17 L}{T}$.

According to these indicators, it is possible to compare the designed control with the known one obtained by the classical variational method with a predetermined optimality criterion

$$
J=\int_{0}^{T} U_{e}^{2}(t) d t
$$

where $\quad U_{e}(t)=\frac{6 L(T-2 t)}{T^{3}}, \quad V_{e}(t)=\frac{6 L t(T-t)}{T^{3}}, \quad S_{e}(t)=\frac{L t(3 T-2 t)}{T^{3}}$.

In this case the indicators are

1. Action according to Lagrange

$$
J_{1}=\int_{0}^{T} V_{e}^{2} d t=\frac{1,2 L^{2}}{T}
$$

2. Control energy intensity

$$
J_{2}=2 \cdot \int_{0}^{T / 2} U_{e}(t) V_{e}(t) d t=\frac{2,25 L^{2}}{T^{2}} .
$$

3. Power norm

$$
J_{3}=\int_{0}^{T} U_{e}^{2} d t=\frac{12 L^{2}}{T^{3}}
$$

4. Energy-action

$$
J_{4}=J_{1} \cdot J_{2}=\frac{2,7 L^{4}}{T^{3}} \text {. }
$$

5. Control graph area (absolute value) $\quad J_{5}=2 \int_{0}^{T / 2} U_{e} d t=\frac{3 L}{T}$.

Attention is drawn to the energy saving, when the designed control was used and the power norm increased in this case. It could lead to misconceptions in effectiveness assessing of the controls, designed by some other criterion (if it was known in advance).

In Figures $1-2$ the graphs of displacement, speed and acceleration (control) are given for the constructed control and classical one. It is important to note that for the designed control the object moves during most of time with a constant speed. Acceleration is characterized by bursts at the initial moment of time during acceleration and at the end during deceleration $(L=1 \mathrm{~m}, T=1.08 \mathrm{~s})$.

In the case of optimal motion of an elastic object with one degree of freedom from the initial state of quiescence to the final state of quiescence, the solution of the differential equation 


$$
\ddot{x}_{r}+k^{2} x_{r}=\frac{-a(T-2 t)^{\prime \prime}}{T^{\prime \prime}}
$$

even at $x_{r}(0)=0$ and $\dot{x}_{r}(0)=0$ is very cumbersome. Therefore, moment ratios $x_{r}(T)=0$, $\dot{x}_{r}(T)=0$ (transcendental equations, for $k=2 T, T_{l}=2 \pi / k, T=T_{l} \cdot n$ ) are not given here, but a graphical searching for one of the common roots is shown in Figure 3.

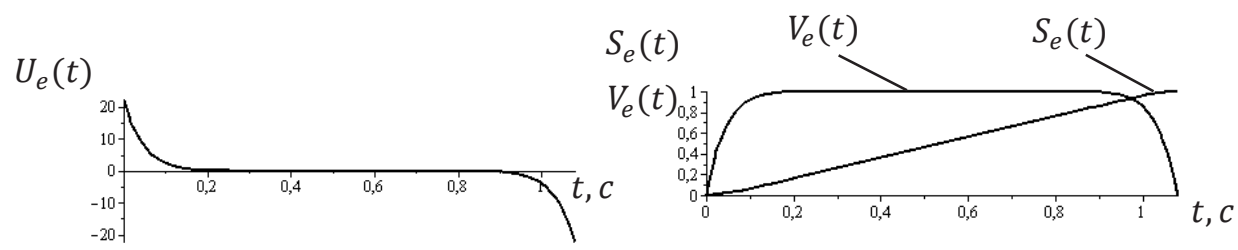

Fig. 1. Graphs $S_{e}(t), V_{e}(t), U_{e}(t)$ for the constructed control

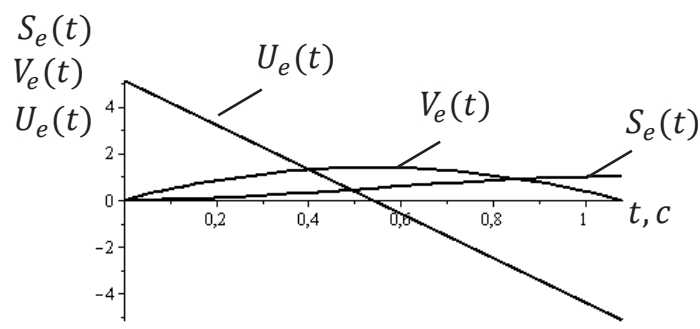

Fig. 2. Graphs $S_{e}(t), V_{e}(t), U_{e}(t)$ for the classical control

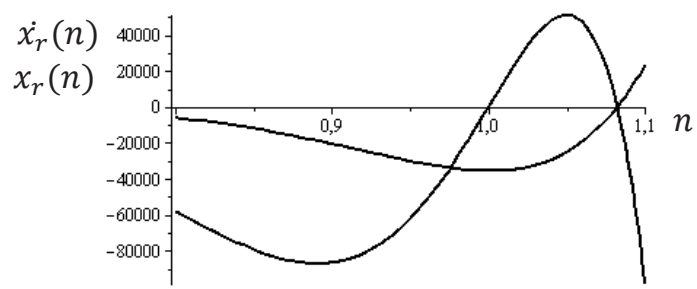

Fig. 3. Graphical searching for one of the common roots

It follows from the graph that $n=1,08$ and $T=1,08 \mathrm{~s}$. During this time, the elastic system makes one complete oscillation (Figure 4) and reaches the state of quiescence.

If $n=2,16$, then $T=2,16 \mathrm{~s}$ and the elastic system also performs two complete oscillations during the translational motion (Figure 5).

An insignificant change in the boundary conditions can lead to an interesting result. Assume that $U_{e}(0)=\frac{6 L}{T^{2}}, U_{e}(T)=-\frac{6 L}{T^{2}}$, that is, we have extreme values taken from the classical control case used for comparison. Keeping the previous conditions, we obtain the following graphs for displacement, speed and acceleration (Figure 6). 


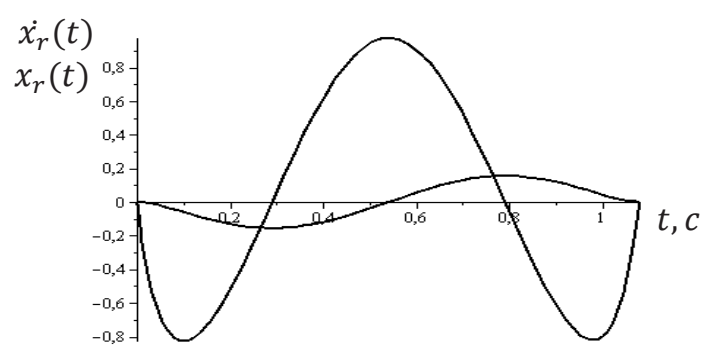

Fig. 4. Oscillations of an elastic object in relative motion

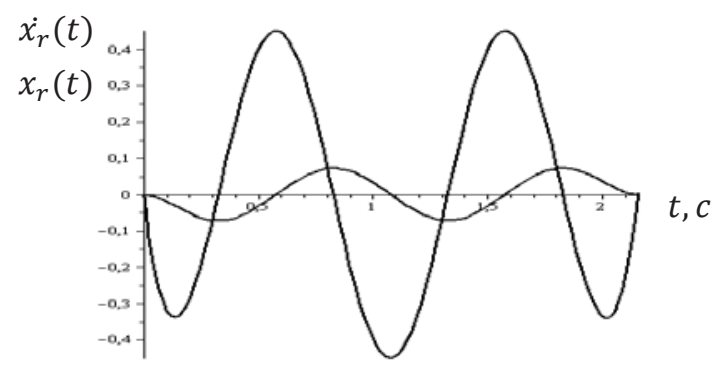

Fig. 5. Oscillations of an elastic object in relative motion
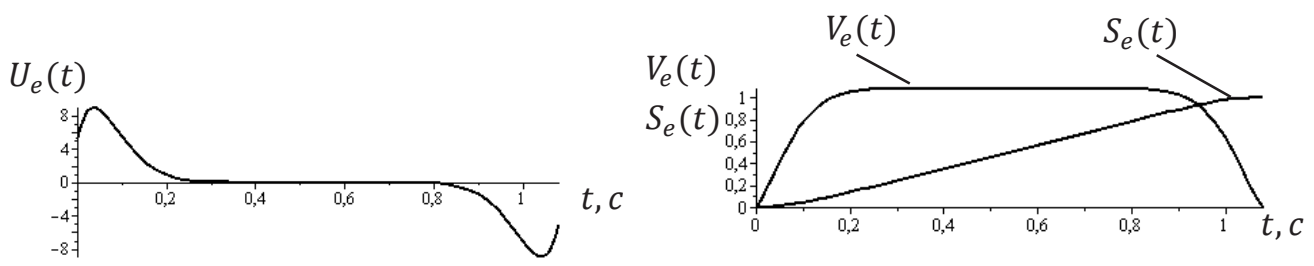

Fig. 6. Graphs $S_{e}(t), V_{e}(t), U_{e}(t)$ for $U_{e}(0)=\frac{6 L}{T^{2}}, U_{e}(T)=-\frac{6 L}{T^{2}}$

It is clear that acceleration and deceleration control has an impulse nature.

To reveal the regularities of the energy consumption decreasing when the degree of the translational acceleration polynomial is increasing, the solutions for the degrees of the polynomial $n_{1}=1,3,5,7,9,11$ are found.

In general, the acceleration is presented in the form:

$$
U(t)=\frac{k L}{T^{2}} \frac{(T-2 t)^{n_{1}}}{T^{n_{1}}},
$$

where $k$ is the acceleration factor, $n$ is the polynomial degree. The results of laborious analytical calculations are summarized in Table 1.

Table 1. The results of laborious analytical calculations

\begin{tabular}{|l|c|c|c|c|c|c|}
\hline Polynomial degree $n_{l}$ & 1 & 3 & 5 & 7 & 9 & 11 \\
\hline Coefficient $k$ & 6 & 10 & 14 & 18 & 22 & 26 \\
\hline Control energy consumption, e & 2,25 & 1,57 & 1,36 & 1,266 & 1,21 & 1,17 \\
\hline
\end{tabular}


The work [12] shows the possibility of the energy consumption reducing for the control implementation by increasing of the acceleration polynomial degree. However, it should be noted that the obtained ratios require additional clarification and correction. In addition, the regression dependence of the energy on the polynomial degree can be corrected more strictly.

According to the Table 1, the dependence of the control energy on the polynomial degree is represented by simple regression law

$$
e=a+\frac{a}{n_{1}}
$$

where $a=\frac{2,25}{2}$.

The graph of the function $e\left(n_{1}\right)$ is given in Figure 7, which confirms the asymptotic property of energy consumption depending on the polynomial degree.

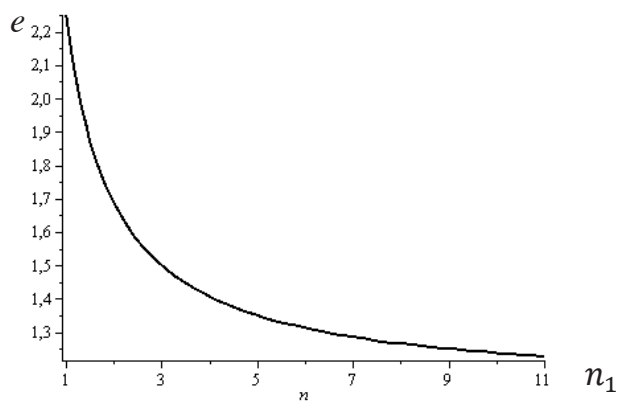

Fig. 7. Dependence of energy on the polynomial degree

\section{Conclusions}

Increasing of the degree of the polynomial used for the constructed control leads to the energy reducing to achieve the motion goal and in the limit (when $n_{1} \rightarrow \infty$ ) it tends to half the energy needed to realize the known control, obtained on the basis of the variational calculus of the optimal control theory (when $n_{l}=1$ ). This pattern is observed for the predetermined time $T$. In practice, it is sufficient to use polynomials with $n_{l}=3,5$.

\section{References}

1. Krasovskij N.N. Teoriya upravleniya dvizheniem. - M.: Nauka, 1968.-476 p.

2. Krut'ko P.D. Obratnye zadachi dinamiki upravlyaemyh sistem: linejnye modeli. - M.: Nauka, 1987. - 304 p.

3. Karnovskij I.A., Pochtman Y.M. Metody optimal'nogo upravleniya kolebaniyami deformiruemyh sistem. - K.: Vyssh. shkola, 1982. - 116 p.

4. Troickij V.A. Optimal'nye processy kolebanij mekhanicheskih sistem. - L.: Mashinostroenie, 1976. - $236 \mathrm{p}$.

5. Chernous'ko F.L., Akulenko P.D., Sokolov B.N. Upravlenie kolebaniyami. - M.: Nauka, 1980. - 384 p.

6. Pontryagin L.S., Boltyanskij V.G., Gamkrelidze R.V. Matematicheskaya teoriya optimal'nyh processov. - M.: Nauka, 1983. - 391 p. 
7. Bokhonsky A.I. Energoemkost' upravleniya peremeshcheniem ob"ektov. Fundamental'nye osnovy mekhaniki: mater. mezhdunar. nauch.-praktich. konf. Novokuzneck: NIC MS, 2017. - P. $38-41$.

8. Bokhonsky A.I., Ryzhkov A.I. Konstruirovanie upravlyaemogo dvizheniya ob"ekta. Mekhanika, avtomatika i robototekhnika: Materialy mezhdunarodnoj nauchnoprakticheskoj konferencii. Novokuzneck: NIC MS, 2017. - N1. - P. 64 - 69.

9. Bokhonsky A.I., Varminskaya N.I., Ryzhkov A.I. Konstruirovanie optimal'nogo upravleniya dvizheniya ob"ektov kak absolyutno tverdyh i deformiruemyh tel. Fundamental'nye i prikladnye problemy tekhniki i tekhnologii. Orel, 3(317) 2016 4(318) 2016. - P. $70-76$.

10. Bokhonsky A.I. Majstrishin M.M. Optimal'nost' konstruiruemyh upravlenij peremeshcheniem ob"ektov. Nauchno-tekhnicheskij zhurnal. Gos. universitet uchebno-nauchno-proizvodstvennyj kompleks. 3(323) 2017. - P. 31 - 38.

11. Bokhonsky A.I. Reversionnyj princip optimal'nosti. - M.: Vuzovskij uchebnik: INFRA-M, 2016. - 174 p.

12. Bokhonsky A.I., Varminskaya N.I. Evaluation of energy consumption for the object motion optimal control). ICMTMTE IOP Conf. Series: Materials Science and Engineering, 709 (2020). 